\title{
Simulating Marine New Particle Formation and Growth Using the M7 Modal Aerosol Dynamics Modal
}

\author{
Ciaran Monahan, ${ }^{1}$ Henri Vuollekoski, ${ }^{2}$ Markku Kulmala, ${ }^{2}$ and Colin O’Dowd ${ }^{1}$ \\ ${ }^{1}$ Centre for Climate and Air Pollution Studies, National University of Ireland Galway, Galway, Ireland \\ ${ }^{2}$ Department of Physics, University of Helsinki, 00014 Helsinki, Finland \\ Correspondence should be addressed to Colin O’Dowd, colin.odowd@nuigalway.ie
}

Received 12 April 2010; Revised 26 August 2010; Accepted 22 September 2010

Academic Editor: Nicholas Meskhidze

Copyright ( 92010 Ciaran Monahan et al. This is an open access article distributed under the Creative Commons Attribution License, which permits unrestricted use, distribution, and reproduction in any medium, provided the original work is properly cited.

\begin{abstract}
A modal atmospheric aerosol model (M7) is evaluated in terms of predicting marine new particle formation and growth. Simulations were carried out for three different nucleation schemes involving (1) kinetic self-nucleation of OIO (2) nucleation via OIO activation by $\mathrm{H}_{2} \mathrm{SO}_{4}$ and (3) nucleation via OIO activation by $\mathrm{H}_{2} \mathrm{SO}_{4}$ plus condensation of a low-volatility organic vapour. Peak OIO and $\mathrm{H}_{2} \mathrm{SO}_{4}$ vapour concentrations were both limited to $6 \times 10^{6}$ molecules $\mathrm{cm}^{-3}$ at noontime while the peak organic vapour concentration was limited to $12 \times 10^{6}$ molecules $\mathrm{cm}^{-3}$. All simulations produced significant concentrations of new particles in the Aitken mode. From a base case particle concentration of $222 \mathrm{~cm}^{-3}$ at radii $>15 \mathrm{~nm}$, increases in concentrations to $366 \mathrm{~cm}^{-3}$ were predicted from the OIO-OIO case, $722 \mathrm{~cm}^{-3}$ for the OIO- $\mathrm{H}_{2} \mathrm{SO}_{4}$ case, and $1584 \mathrm{~cm}^{-3}$ for the OIO- $\mathrm{H}_{2} \mathrm{SO}_{4}$ case with additional condensing organic vapours. The results indicate that open ocean new particle production is feasible for clean conditions; however, new particle production becomes most significant when an additional condensable organic vapour is available to grow the newly formed particles to larger sizes. Comparison to sectional model for a typical case study demonstrated good agreement and the validity of using the modal model.
\end{abstract}

\section{Introduction}

Aerosols are ubiquitous in the Earth atmosphere and have measurable impacts on climate, atmospheric chemistry, and human health [1]. Marine aerosols are thought to have a potentially significant role in future climate change through biogeochemical feedback processes [2]. The aforementioned studies focussed on biogenic DMS-derived sulphate driving marine new particle formation and subsequent growth into cloud condensation nuclei (CCN) sizes $(r>35-50 \mathrm{~nm})$.

Detailed modelling studies [3] have, however, demonstrated that while sulphuric acid is present in sufficient concentrations to promote nucleation, the concentration is insufficient to grow these nucleated clusters into aerosol particles operationally defined as $D>3 \mathrm{~nm}$.

An increase in marine aerosol concentration, providing the increased aerosol population is water soluble, can potentially lead to an increase in $\mathrm{CCN}$; however, there are three stages to growth. The first stage involves nucleation of stable or critical clusters; the second stage involves the growth of clusters into pseudostationary aerosol particles where they can survive significantly longer than clusters (e.g., if a particle grows to $6 \mathrm{~nm}$ in size, it has the potential to survive at least 100 times longer than a cluster of $0.5 \mathrm{~nm} \mathrm{[4];} \mathrm{the} \mathrm{third} \mathrm{stage} \mathrm{is} \mathrm{continued} \mathrm{growth} \mathrm{to} \mathrm{CCN}$ sizes. There has been little evidence to date demonstrating that these growth processes can be achieved through the sulphur cycle. Furthermore, oceanic new particle production events are difficult to quantify in comparison to terrestrial events. Coastal zones, in contrast, provide typically stronger biogenic signals and possibly are scalable to, and indicative of, difficult-to-detect open ocean processes. A case and example of this is the formation of new particles in the tidal and/or coastal where macro algae biogenic gas emissions are the strongest [4-7]. O'Dowd and Hoffmann [7] provide an informed overview of coastal new particle production driven by the release of molecular iodine and its subsequent photolysis and oxidation by ozone. 
More recently, a number of studies have been carried out on the nucleation and growth capabilities of iodine oxides $[8,9]$ where it has been found that iodine oxides have the potential to make significant contribution to the formation of new particles as well as contributing to a considerable increase in growth rates of newly formed stable clusters. More recently, simulations using a sectional model on iodine dioxide nucleation in coastal and open ocean marine environments found that particle production driven by iodine compounds is possible, but by $\mathrm{OIO}$ and $\mathrm{H}_{2} \mathrm{SO}_{4}$ alone, only few particles are likely to reach detectable sizes without an additional low volatility vapour, owing to the scavenging by coagulation processes with the existing aerosol population [10].

In the examination of the nucleation mechanisms relating to iodine oxides presented in this work, three parameterisations from Vuollekoski et al. [10], that include both iodine oxide and an additional nonnucleating organic condensable vapour, are investigated. The M7 [11] atmospheric microphysics aerosol module has been used to incorporate firstly iodine oxide (OIO) self-nucleation, secondly iodine oxide-sulphuric acid nucleation, and thirdly, iodine oxide-sulphuric acid nucleation with additional condensation of a low volatility organic vapour. The iodine oxide self-nucleation is a kinetic mechanism while the iodine oxide-sulphuric acid mechanism represents activation of iodine oxide by sulphuric acid vapours.

Recent results from the NE Atlantic reported the occurrence of open ocean particle production and growth events [12-14]. The latter study points to a condensable vapour source concentration of the order of $1.2 \times 10^{7}$ molecules $\mathrm{cm}^{-3}$ to explain typical growth rates of $0.8 \mathrm{~nm} \mathrm{hour}^{-1}$ observed. This study builds on the aforementioned sectional modelling sensitivity studies by Vuollekoski et al. [10] and the new experimental data to evaluate the ability of the M7 modal model to reproduce the experimental observations and to simulate these with the same skill as a detailed sectional model.

\section{Model Setup}

The model used to perform the simulations in this study was the M7 atmospheric microphysics aerosol box model [11]. The M7 module was designed to be coupled with general circulation models and chemistry transport models. In M7 the aerosol populations is divided into two groups: mixed (water-soluble) particles, and insoluble particles. The model separates the aerosol populations into seven classes according to the dry radius size of the particles.

A "pseudomodal" approach is used to describe the aerosol populations and to determine the aerosol dynamics. The mixed aerosol size distribution over different size ranges is represented by four lognormal modes: nucleation $(0.5-5 \mathrm{~nm})$, Aitken $(5 \mathrm{~nm}-50 \mathrm{~nm})$, accumulation (50 nm$500 \mathrm{~nm})$, and coarse modes $(>500 \mathrm{~nm})$, while the rate constants for coagulation and condensation are calculated for the average mode radius rather than the integral over the mode. The geometric standard deviations of these modes are 1.59 for the nucleation, Aitken, and accumulation modes, both soluble and insoluble, while the coarse have a geometric standard deviation of 2.0 for the soluble and insoluble modes [11].

The aerosol species considered in the M7 module are mineral dust, black carbon (BC) and primary organic carbon, sulphate, and sea salt. The aerosol dynamic processes in M7 include nucleation, coagulation, and condensation of sulphuric acid. Mixed (or soluble) particles are formed from insoluble particles by coagulation and condensation.

In the M7 model, it is assumed that the mixed particles are a water-soluble mixture of insoluble and soluble material. The separation of the aerosol populations into these two populations allows for the representation of the evolution of the hygroscopic properties of the initially insoluble compounds, on which their atmospheric lifetimes and also their interaction with clouds depend.

For this study, the box model was modified to include two new vapour species, iodine oxide along with a lowvolatility organic vapour species, and also the aerosol processes adapted to allow for the condensation of both these vapours, as well as the nucleation of iodine oxide and activation nucleation of iodine oxide by sulphuric acid. For the duration of each simulation, clear sky conditions were assumed.

Both OIO and condensing organic vapour are treated as $\mathrm{H}_{2} \mathrm{SO}_{4}$, but with an alternative molar mass and molecular density. The OIO is considered to possess a molar mass of $158.90 \mathrm{~g} / \mathrm{mol}$ with a molecular density of $4.98 \mathrm{~g} / \mathrm{mol}$, while the organic vapour is considered to have more sulphurderived properties, having a molar mass and molecular density of $98.08 \mathrm{~g} \mathrm{~mol}^{-1}$ and $1.84 \mathrm{~g} / \mathrm{cm}^{3}$, respectively. The transfer of sulfate, OIO, and the condensable organic vapour to the particles is based on Fuchs [15]. Mass transfer from the vapour species to the soluble and insoluble particles are distinguished by different mass accommodation coefficients, 1.0 for soluble and 0.3 for insoluble modes. The change in the mass due to nucleation and condensation of the vapour compounds are integrated over each time step. The vapour species are assumed to condense on all modes, resulting in a net increase of the mean modal radius.

Simulations were carried out to simulate nucleation occurring in typical marine conditions, using two of the parameterized nucleation schemes presented in Vuollekoski et al. [10] iodine-driven kinetic nucleation $\left(K_{1} \times[\mathrm{OIO}] \times\right.$ $[\mathrm{OIO}])$ and particle formation deriving from sulfuric acidiodine-driven activation nucleation $\left(\mathrm{K}_{2} \times\left[\mathrm{H}_{2} \mathrm{SO}_{4}\right] \times[\mathrm{OIO}]\right)$ [10]. The values for the kinetic parameters $K_{1}$ and $K_{2}$ were estimated by simulation of the observed aerosol formation bursts in the vicinity of Mace Head research station with an aerosol dynamical box model. The recommended values of these parameters are $3 \times 10^{-12}\left(3.5 \times 10^{-13}--3.5 \times\right.$ $\left.10^{-10}\right) \mathrm{cm}^{3} \mathrm{~s}^{-1}$ for $K_{1}$ and $3 \times 10^{-10} \mathrm{~cm}^{3} \mathrm{~s}^{-1}$ for $K_{2}$.

In the presented simulations, the new particle formation arising from the contribution of the iodine oxides was assumed to occur during daylight hours, when marine halogen emissions were exposed to incoming solar radiation. Due to the lack of information on the quantities or the timescales involved in biogenic precursor gas emissions, it was assumed that emissions would be at a minimum at sunrise and 


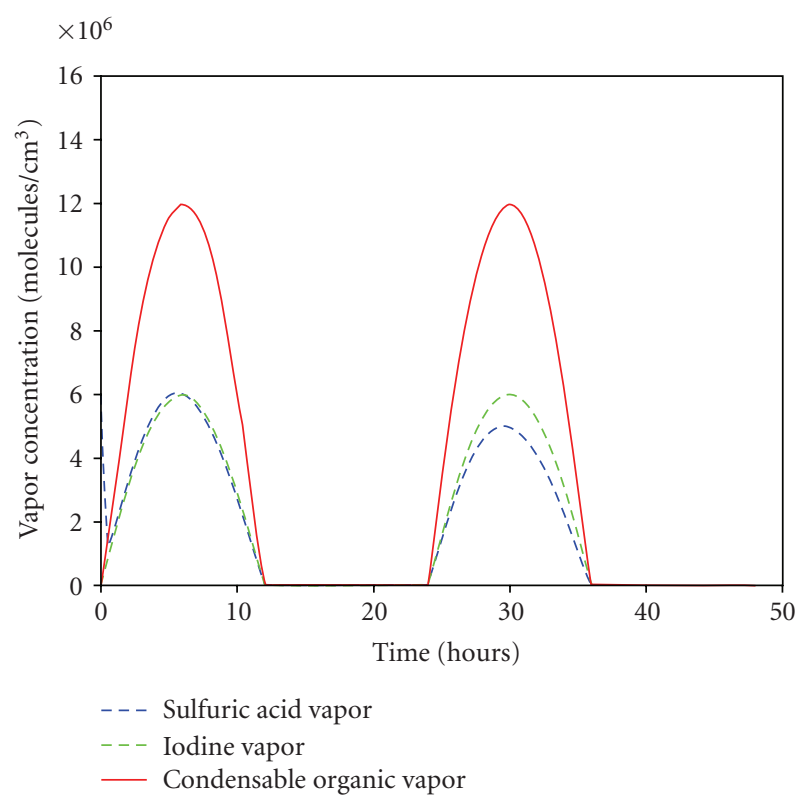

FIGURE 1: Concentrations of vapour species taken over 48 hours of simulation time.

sunset, reaching a peak around midday when incoming solar radiation is at its maximum. In the simulations where a condensable organic vapor is also present, its concentration, presented in Figure 1, was assumed to follow the same scheme, as this gas is also assumed to come about from biological production.

Throughout all simulations presented in this study, the peak sulphuric acid vapor concentration was $6 \times$ $10^{6}$ molecules $\mathrm{cm}^{-3}$, [16] with the peak iodine oxide vapor also being $6 \times 10^{6}$ molecules $\mathrm{cm}^{-3}$, while the peak concentration of the additional organic vapor, when present, was $1.2 \times 10^{7}$ molecules $\mathrm{cm}^{-3}$. The iodine oxide peak value is taken somewhat as arbitrary, noting that sensitivities were evaluated in Vuollekoski et al. [10]. The organic vapour concentration estimate is taken from [14].

The initial aerosol populations were also setup so as to describe typical clean marine background concentrations. While no particles were assumed to be present in the nucleation mode $(0.5 \mathrm{~nm}-5 \mathrm{~nm})$, the initial loadings of the other size ranges were 200 particles $\mathrm{cm}^{-3}$ for the Aitken $(5 \mathrm{~nm}-$ $50 \mathrm{~nm}$ ) size range, 100 particles $\mathrm{cm}^{-3}$ for the accumulation $(50 \mathrm{~nm}-500 \mathrm{~nm})$ size range, and 2 particles $\mathrm{cm}^{-3}$ for the coarse (larger than $500 \mathrm{~nm}$ ) size range. All of the mass in the coarse mode is assumed to be sea salt, corresponding to a wind speed of approximately $7 \mathrm{~m} \cdot \mathrm{s}^{-1}$. In the smaller size ranges, aerosol composition was assumed to be sulfate. For these parameters, the Aitken mode was initially centered $\sim 16 \mathrm{~nm}$, the accumulation mode $\sim 75 \mathrm{~nm}$, and the coarse mode around $\sim 700 \mathrm{~nm}$.

For comparison, the sectional model used by Vuollekoski et al. [10] was setup to run with the assumptions used in this paper. The model is based on the UHMA model (University of Helsinki Multicomponent Aerosol model, [17]), which is a size-segregated box model incorporating all basic aerosol dynamical processes: nucleation, condensation, coagulation and dry deposition.

\section{Results}

3.1. General Simulations. Simulations were conducted over a 48 -hour time period. The first simulation was carried out for condensing sulphuric acid and no nucleation as a base case scenario. This base case was completed with final concentrations of 171 particles $\mathrm{cm}^{-3}$ for the Aitken mode, 105 particles $\mathrm{cm}^{-3}$ for the accumulation, and 2 particles $\mathrm{cm}^{-3}$ for the coarse modes, reflecting some coagulation loss in the Aitken mode along with growth of Aitken mode sizes into the accumulation mode over the 48-hour period. The contour plot of the size distribution over the period is shown in Figure 2. The number concentrations at sizes larger than $15,25,35$ and $50 \mathrm{~nm}$ radius were 222 , 150,121 , and $110 \mathrm{~cm}^{-3}$, respectively (Table 1 ). The second simulation related to iodine oxide self-nucleation $\left(K_{1} \times\right.$ $[\mathrm{OIO}] \times[\mathrm{OIO}])$. The size distribution evolution is shown in Figure 2, and the nucleation mode and Aitken mode particle concentrations are shown in Figure 3(a) where it can be seen that the simulation resulted in moderately highnumber concentrations in the nucleation mode, reaching a maximum of $7000 \mathrm{~cm}^{-3}$ during the first day, and $5000 \mathrm{~cm}^{-3}$ on the second day. For the Aitken mode, peak concentrations of $260 \mathrm{~cm}^{-3}$ are seen on the first day, rising to $430 \mathrm{~cm}^{-3}$ on the second day. Number concentrations larger than 15, 25,35 , and $50 \mathrm{~nm}$ radius were $366,196,134$, and $110 \mathrm{~cm}^{-3}$, respectively (Table 1).

Model runs using the sulfuric acid-iodine-driven nucleation $\left(\mathrm{K}_{2} \times\left[\mathrm{H}_{2} \mathrm{SO}_{4}\right] \times[\mathrm{OIO}]\right)$ exhibited higher number concentrations compared to the OIO-OIO simulations. The evolving size distribution is shown in Figure 2, and the nucleation mode and Aitken mode concentrations are shown in Figure 3(b). The nucleation mode peaks at about $46,000 \mathrm{~cm}^{-3}$ on the first day, and on the second day the peak is just below $42,000 \mathrm{~cm}^{-3}$. The Aitken mode after the mid day peak in the production of OIO, with peak concentrations reaching $900 \mathrm{~cm}^{-3}$ on the first day, increased to $1568 \mathrm{~cm}^{-3}$ on the second day. By the end of the simulation, the number concentrations at sizes larger than $15,25,35$, and $50 \mathrm{~nm}$ radius were $722,243,136$ and $110 \mathrm{~cm}^{-3}$, respectively (Table 1).

The final simulation was for $\mathrm{H}_{2} \mathrm{SO}_{4}$-OIO plus a condensing organic vapour. Again, the evolving size distribution is illustrated in Figure 2 and the nucleation mode and Aitken mode concentrations are shown in Figure 3(c). For this simulation, similar peak nucleation concentrations were seen to the $\mathrm{H}_{2} \mathrm{SO}_{4}$-OIO case on day one and slightly less on day two. The Aitken mode, in contrast, shows significantly higher peak concentrations with $>2500 \mathrm{~cm}^{-3}$ achieved on day one and $3026 \mathrm{~cm}^{-3}$ on day 2 . By the end of the simulation, the number concentration at sizes larger than $15,25,35$, and $50 \mathrm{~nm}$ radius were $1585,556,230$, and $126 \mathrm{~cm}^{-3}$, respectively.

The change in the Aitken mode radius for the three simulations involving nucleation is shown in Figure 4. At the start of the simulation, the mode radius is $15.8 \mathrm{~nm}$ and increases to approximately $18 \mathrm{~nm}$ in all three cases. 
TABLE 1: Comparison of absolute particle number concentrations increases for particles of radii more than 50, 35, 25, and $15 \mathrm{~nm}$, using the different nucleation schemes, taken over 48 hours at vapor concentrations of $6 \times 10^{6} \mathrm{molec} \cdot \mathrm{cm}^{-3}$ for the sulphuric acid and iodine along with $12 \times 10^{6} \mathrm{molec} \cdot \mathrm{cm}^{-3}$ for the nonnucleating organic vapor.

\begin{tabular}{|c|c|c|c|c|}
\hline Radius (nm) & $\begin{array}{l}\text { Number } \\
\text { concentration }\left(\mathrm{cm}^{-3}\right) \\
\mathrm{H}_{2} \mathrm{SO}_{4} \text { only (no } \\
\text { nucleation) }\end{array}$ & $\begin{array}{l}\text { Number } \\
\text { concentration }\left(\mathrm{cm}^{-3}\right) \\
\text { OIO-OIO }\end{array}$ & $\begin{array}{l}\text { Number } \\
\text { concentration }\left(\mathrm{cm}^{-3}\right) \\
\mathrm{H}_{2} \mathrm{SO}_{4} \text {-OIO }\end{array}$ & $\begin{array}{l}\text { Number } \\
\text { concentration }\left(\mathrm{cm}^{-3}\right) \\
\mathrm{H}_{2} \mathrm{SO}_{4} \text {-OIO-COV }\end{array}$ \\
\hline$>15$ & 221.5 & 366.1 & 722.3 & 1584.5 \\
\hline$>25$ & 150.4 & 196.0 & 243.1 & 556.3 \\
\hline$>35$ & 121.0 & 133.5 & 135.9 & 229.6 \\
\hline$>50$ & 109.5 & 111.2 & 110.0 & 125.6 \\
\hline Radius (nm) & $\begin{array}{l}\text { Percentage increase } \\
\mathrm{H}_{2} \mathrm{SO}_{4} \text { only ( } \mathrm{No} \\
\text { nucleation) }\end{array}$ & $\begin{array}{l}\text { Percentage increase } \\
\text { OIO-OIO }\end{array}$ & $\begin{array}{l}\text { Percentage increase } \\
\mathrm{H}_{2} \mathrm{SO}_{4} \text {-OIO }\end{array}$ & $\begin{array}{l}\text { Percentage increase } \\
\mathrm{H}_{2} \mathrm{SO}_{4} \text {-OIO-COV }\end{array}$ \\
\hline$>15$ & - & $65 \%$ & $226 \%$ & $615 \%$ \\
\hline$>25$ & - & $30 \%$ & $62 \%$ & $270 \%$ \\
\hline$>35$ & - & $10 \%$ & $12 \%$ & $90 \%$ \\
\hline$>50$ & - & $2 \%$ & $0.5 \%$ & $15 \%$ \\
\hline
\end{tabular}

The OIO-OIO simulation takes the longest time to reach $18 \mathrm{~nm}$ while, as expected, the most rapid initial growth is seen for the case with the condensing organic vapour. After the mode reaches $18 \mathrm{~nm}$, there is a sudden drop to approximately $12 \mathrm{~nm}$ in all cases, albeit at different rates. The drop results from the nucleation mode growing into the Aitken mode and reducing the mean or modal radius. Thereafter, the Aitken mode grows continuously to the end of the simulations with peak growth rates observed for all simulations during the rise in concentration of vapours associated with the second day's photochemical cycle.

For the accumulation mode, there is a marginal decrease in mode radius; however, as stated above, there is still a significant increase $(15 \%)$ in particle concentration at sizes $>50 \mathrm{~nm}$ and $90 \%$ at sizes larger than $35 \mathrm{~nm}$. For the base case without nucleation but with $\mathrm{H}_{2} \mathrm{SO}_{4}$-driven growth, maximum growth rates, in daylight hours, of $0.11 \mathrm{~nm} \mathrm{hour}^{-3}$ is achieved. By comparison, with OIO nucleation and growth, combined with $\mathrm{H}_{2} \mathrm{SO}_{4}$ growth, growth rates achieved are $0.17 \mathrm{~nm}$ hour ${ }^{-1}$. For the $\mathrm{H}_{2} \mathrm{SO}_{4}$ activation of OIO, subsequent growth reaches $0.3 \mathrm{~nm}_{\text {hour }}{ }^{-1}$, while the final case with additional condensable vapors, the maximum growth rate achieved, is $0.48 \mathrm{~nm}_{\text {hour }}^{-1}$. Night time growth rates range from $0.002 \mathrm{~nm} h o u r^{-1}$ for the base case to $0.072 \mathrm{~nm}_{\text {hour }}{ }^{-1}$ for the organic vapor case.

The nucleation scheme involving sulfuric acid and iodine in the presence of organic condensable vapor is, not surprisingly, the most effective particle formation scheme, yielding particle concentrations of more than $3000 \mathrm{~cm}^{-3}$ in the Aitken mode. This scheme also produces the higher growth rates for both particles in the nucleation and Aitken modes. This increased particle number concentration and growth rates are due to the growth rate enhancement triggered by the additional organic vapor, allowing nucleation mode particles to grow more rapidly to larger and more stable size ranges. This also leads to an initial low Aitken mean modal radius as new particles grow from the nucleation mode.
The OIO-OIO scheme exhibits the smallest peak particle number concentration compared to either of the other schemes, primarily due to the most rapid depletion of OIO, leaving much less vapour to condense on newly nucleated clusters and to grow them to stable sizes. This is also evident in a detailed examination of the mean particle radius for various size ranges within the Aitken mode.

\section{Comparison of Modal and Sectional Models}

A particular case study of an extended growth event is presented by way of comparison between modelled events and those measured. The presented event illustrates growth over a time exceeding 24 hours from JD236 to JD238. Particles with a modal peak at $\sim 15 \mathrm{~nm}$ are deleted at the beginning of JD236 and continue to grow throughout the following 48 hours to almost $25 \mathrm{~nm}$ in radius. This welldefined episode, characterised by very high concentrations of nucleation mode particles in the $1.5-3 \mathrm{~nm}$ range, is in the absence of either anthropogenic modification or coastal nucleation events. Analysing this extended growth period, suitable numbers can be acquired to reproduce this event from a modelling approach.

Recent open ocean nucleation studies have pointed to a lifetime of approximately 15 hours before detection [14]. A nucleation event was therefore simulated using the $\mathrm{H}_{2} \mathrm{SO}_{4}$ OIO-COV scheme beginning 15 hours before detection time in order to test the validity of the model. Modal radii and concentration were then compared. Peak vapour concentrations of $6 \times 10^{6}, 6 \times 10^{6}$, and $1.8 \times 10^{7} \mathrm{molec} \cdot \mathrm{cm}^{-3}$ were used for the concentration of $\mathrm{H}_{2} \mathrm{SO}_{4}$, OIO, and the $\mathrm{COV}$ respectively. A vapour concentration of $1.8 \times 10^{7} \mathrm{molec} \cdot \mathrm{cm}^{-3}$ was used in this case study as this was found to better simulate the growth of the open ocean plume case study than the $1.2 \times 10^{7}$ molec $\cdot \mathrm{cm}^{-3}$ value used in initial simulations. This differs from the value calculated by O'Dowd et al. [14] 

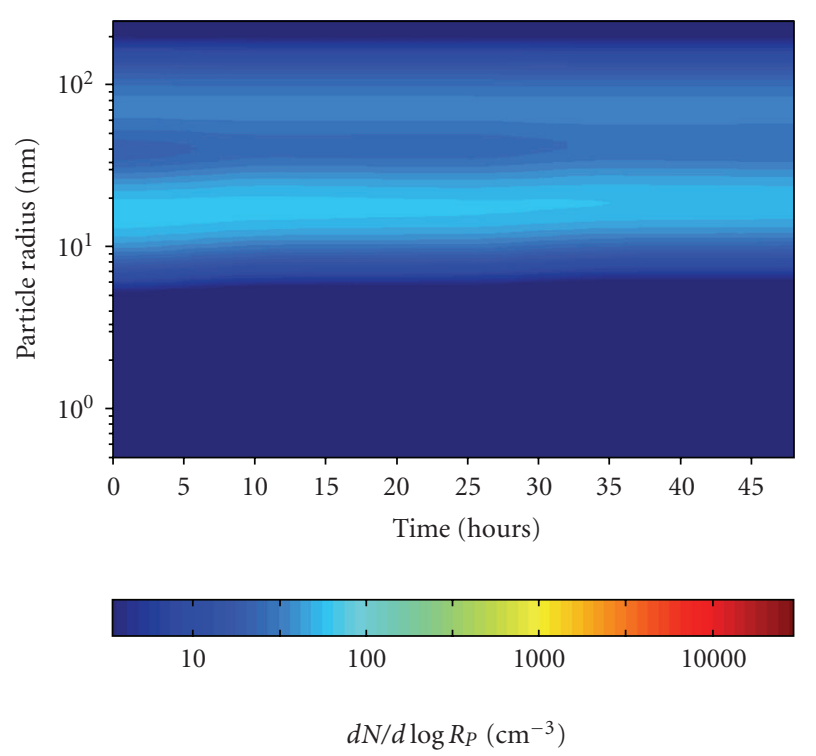

(a)

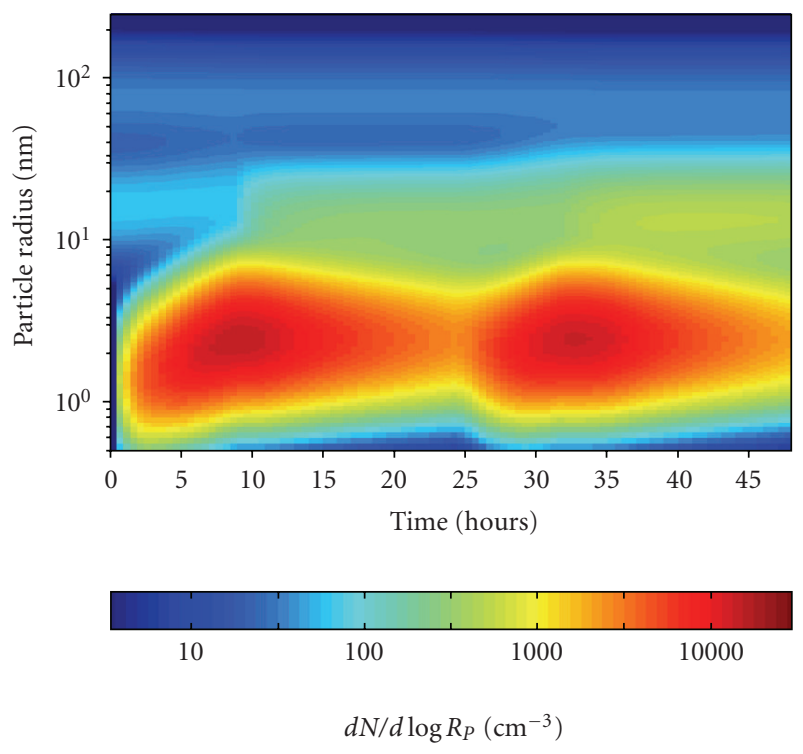

(c)
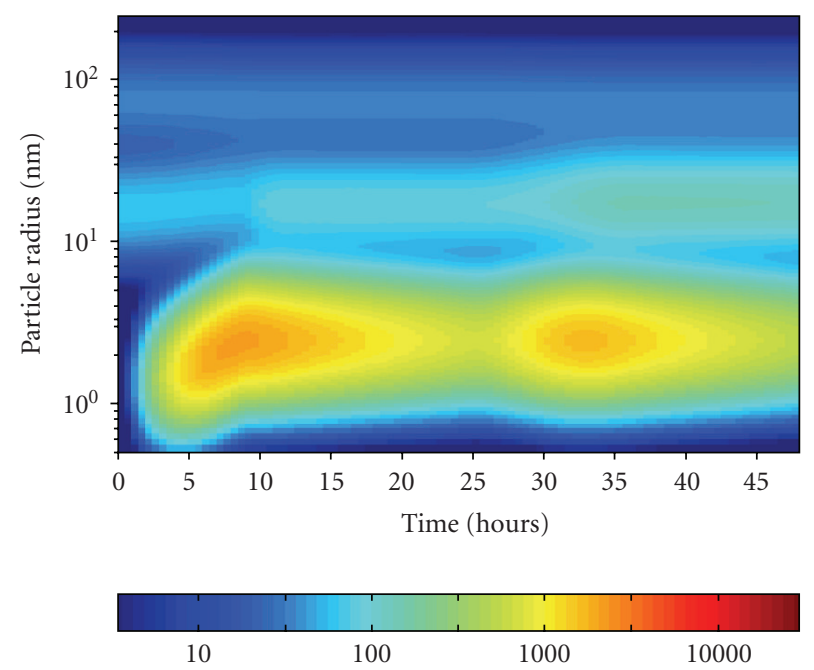

$d N / d \log R_{P}\left(\mathrm{~cm}^{-3}\right)$

(b)

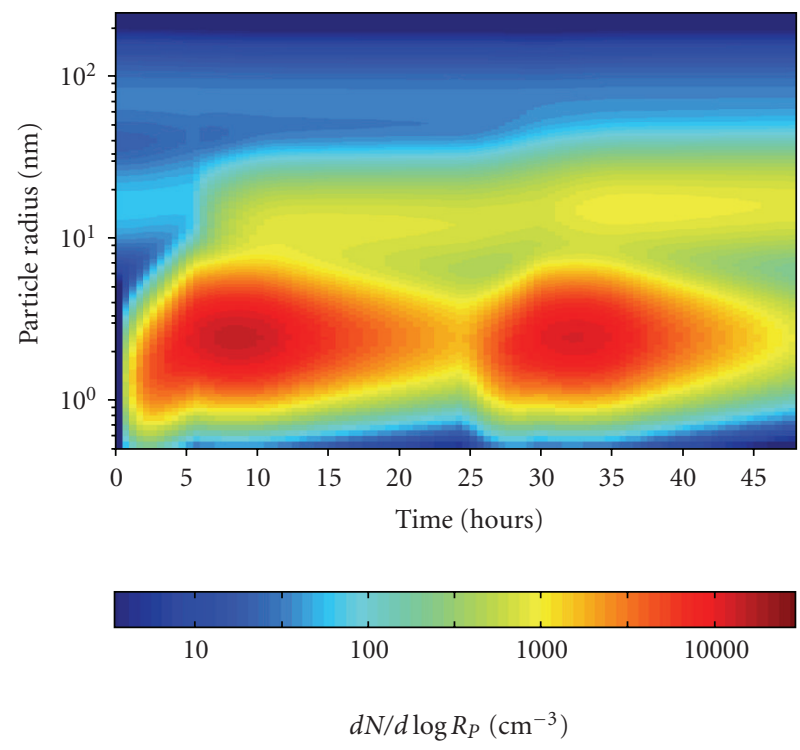

(d)

FIGURE 2: (a) Base case of $\mathrm{H}_{2} \mathrm{SO}_{4}$ growth without nucleation (b) kinetic self (OIO) nucleation and growth (c) $\mathrm{H}_{2} \mathrm{SO}_{4}$-OIO nucleation and (d) $\mathrm{H}_{2} \mathrm{SO}_{4}$-OIO nucleation plus condensation of organic vapours.

$\left(1.2 \times 10^{7}\right.$ molecules $\left.\mathrm{cm}^{-3}\right)$ marginally and can be attributed to differences in the measured and modelled size distribution condensation sinks. Vapour concentrations were assumed to have a daily sinusoidal concentration as in previous simulations.

The developing size distributions are shown in Figure 5, and some key differences in the modal and sectional approaches are evident. The modal model will transfer particles from one mode to the adjacent mode if the lognormal size distribution has grown a sufficient amount so as to intersect the adjacent mode. This process is evident in Figure 5(b) in which we see an increases in the Aitken mode concentration during a growth period, but a decrease in the mean mode radius of the nucleation mode as the larger particles are transferred to the Aitken mode. The sectional model in contrast has a steady growth of the nucleation mode into the Aitken size range.

The Aitken mode concentration and mode radius are compared in Figure 6. The modal model's Aitken mode concentration is lower in comparison with the sectional model; however there is a higher degree of correlation between the modal model and that measured. The sectional 


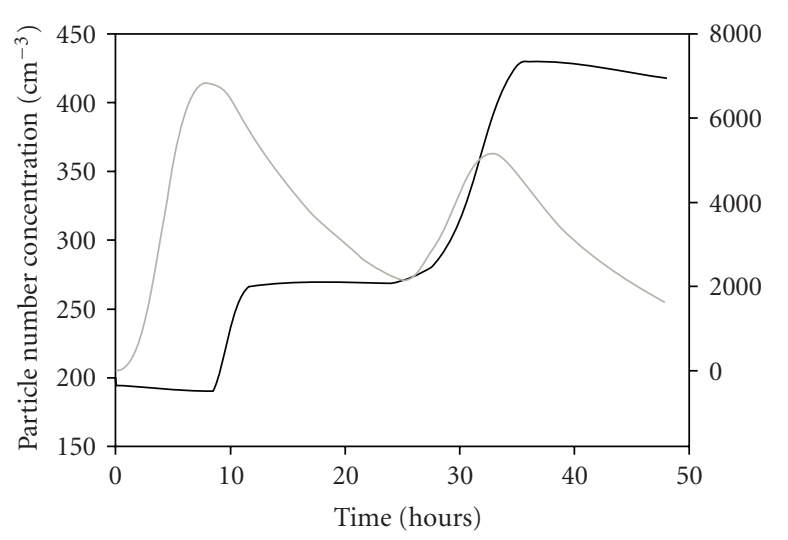

(a)

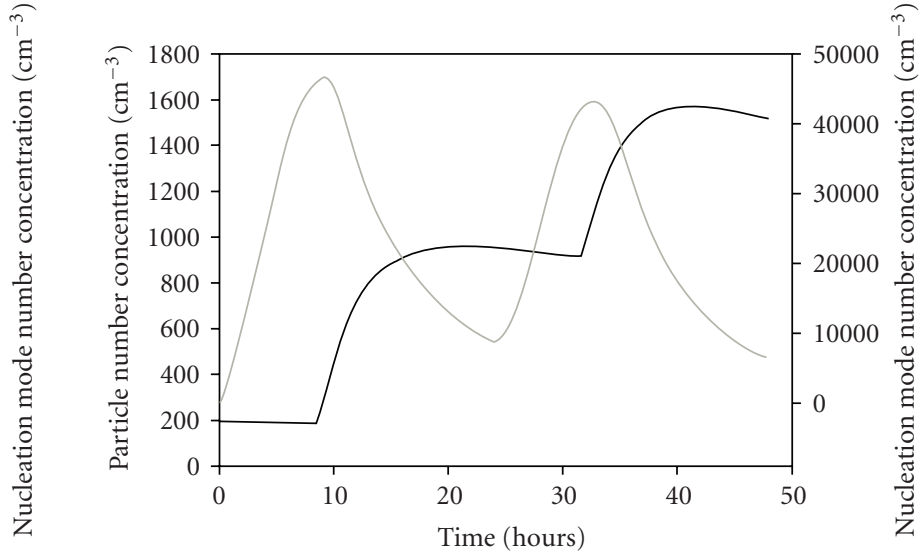

(b)

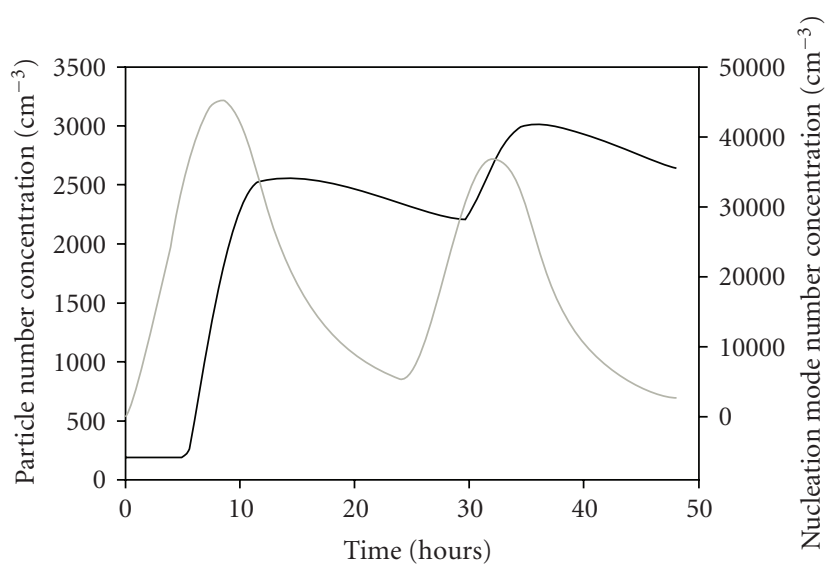

_ Aitken mode particle number concentration Nucleation mode particle number concentration

(c)

Figure 3: (a) Particle concentrations from the iodine oxide self-nucleation scheme nucleation scheme taken over 48 hours at maximum OIO vapor concentrations of $6 \times 10^{6}$ molecules $\mathrm{cm}^{-3}$. (b) Particle concentrations from the sulfuric acid-iodine-driven nucleation schemes taken over 48 hours at maximum vapor concentrations of $6 \times 10^{6}$ molecules $\mathrm{cm}^{-3}$ for both vapors. (c) Particle concentrations of sulfuric acid-iodine-based nucleation scheme in the presence of organic condensable vapor nucleation schemes taken over 48 hours at maximum vapor concentrations of $6 \times 10^{6}$ molecules $\mathrm{cm}^{-3}$ for the sulphuric acid and iodine, along with a maximum of $12 \times 10^{6} \mathrm{molecules}^{-3}$ for the nonnucleating organic vapor.

model has a higher Aitken mode concentration due to a more constant growth of nucleation mode particles. Examining Figure 6(b) it can be seen that there was reasonably good correlation between the mode radii of the modal and sectional models. Both models however exhibit a larger mode radius than that of measured events, with radii at the end of the simulation of $16 \mathrm{~nm}, 23 \mathrm{~nm}$, and $27 \mathrm{~nm}$ for the measured, modal and sectional plumes, respectively. There is a somewhat higher modal radius in the sectional model results over the measurement period; however this is mainly due to the merging of the nucleation and Aitken mode when the nucleation mode particle population has grown to comparable sizes. The modal model results show lower numbers during the measurement period mainly due to the aforementioned differences in the modal and sectional techniques, leading to lower numbers of instances of modal merging.

\section{Discussion}

These findings are in qualitative agreement with those of Vuollekoski et al. [10] who also found, using a sectional aerosol model and some different assumptions relating to the environmental conditions that iodine oxide nucleation did lead to significant nucleation, but very few of the newly formed particles grow to large sizes without the presence of a low-volatility organic vapor. Vuollekoski et al. [10] suggested that condensable vapours with concentrations of the order of $10^{6}$ molecules $\mathrm{cm}^{-3}$ were sufficient for noteable particle production. The current results suggest that concentrations as low as $\sim 10^{7}$ molecules $\mathrm{cm}^{-3}$ can still have a modest but notable $(10 \%)$ increase in particle concentrations larger that $50 \mathrm{~nm}$ radius and $90 \%$ for sizes larger than 35\%. Vuollekoski et al. [10] also suggested that iodine oxides were likely to lead to cloud condensation nuclei sizes if air had advected 


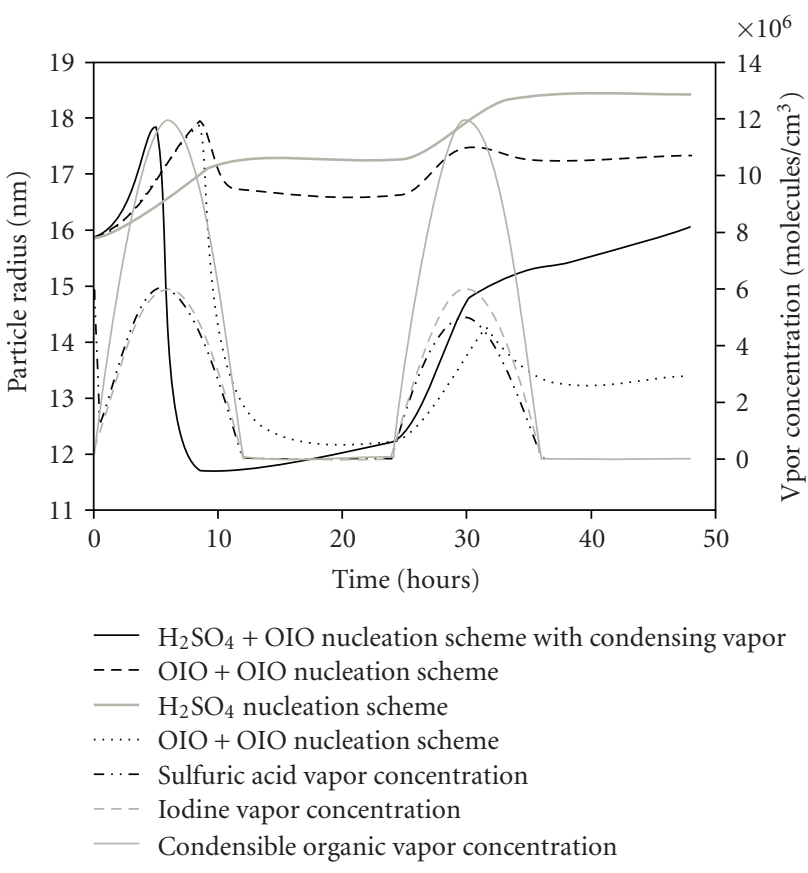

Figure 4: Comparison between aitken mode particle radii of the different nucleation schemes (on the left)

over large plankton blooms extending over hundreds of kilometres where sustained iodine oxide production could prevail. While the OIO concentrations in this study have been arbitrarily chosen, they represent the concentration fields required to have a noninsignificant impact on the marine aerosol population, particularly at sizes larger that $35 \mathrm{~nm}$ and $50 \mathrm{~nm}$ radius where they can contribute to the marine cloud condensation nuclei population.

Recent work has revealed that open-ocean new particle formation and growth events are not uncommon over biologically-rich oceans such as the North East Atlantic $[13,14]$. O'Dowd et al. [14] document some typical example of continuous growth over periods of up to 48 hours and calculated growth rates of the order of $0.8 \mathrm{~nm}$ hour $^{-1}$ whereas Ehn et al. [13] reported an average growth rate over four events of $3 \mathrm{~nm}$ hour $^{-1}$. The O'Dowd et al. [14] events show, more or less, constant growth throughout the 48-hour period, even at night time, while the study here shows high growth rates during daylight hours as condensable vapours are produced. Perhaps the reason constant growth relates to the increased ability for some organic molecules to condense to larger particles leading to a scenario whereby the lower volatility organics are condensing to the smallest particles during daytime while a reservoir of more volatile particles are accumulating to become available at night time and when the growing particles get larger and the Kelvin effect lesser.

\section{Conclusions}

Three nucleation schemes involving iodine oxides were implemented in the modal aerosol model M7 to explore the feasibility of iodine oxides contributing to marine new

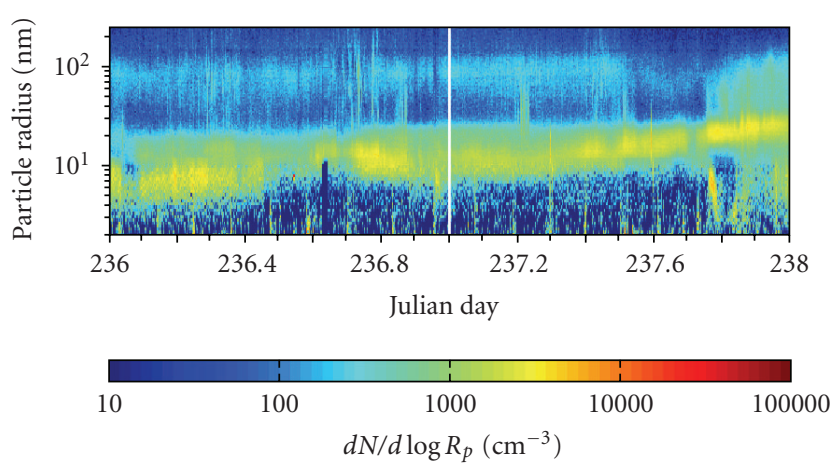

(a)

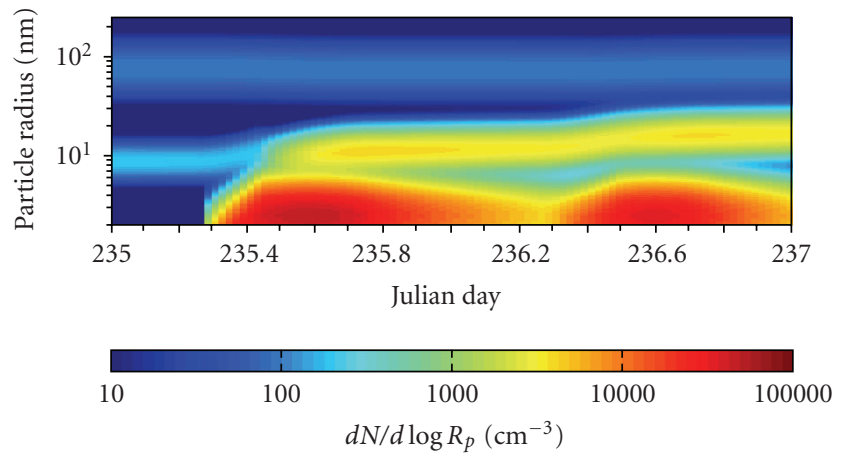

(b)

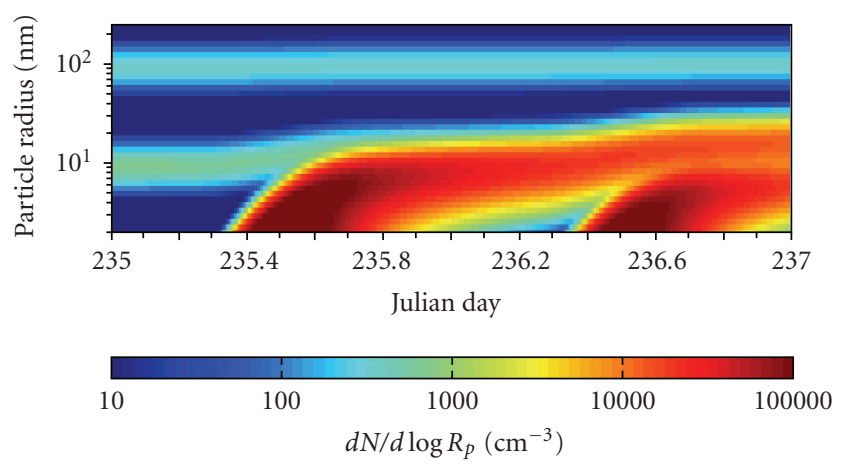

(c)

Figure 5: (a) Recorded open ocean nucleation event, (b) a modeled nucleation event beginning 15 hours before plume detection using modal model, and (c) a modeled nucleation event beginning 15 hours before plume detection using sectional model.

particle formation and growth. The two nucleating species considered were $\mathrm{OIO}$ and $\mathrm{H}_{2} \mathrm{SO}_{4}$, each with a midday peak concentration of $6 \times 10^{6}$ molecules $\mathrm{cm}^{-3}$, decreasing to zero at sunrise and sunset. A kinetic OIO self-nucleation scheme was found to increase the background aerosol population $\left(N=300 \mathrm{~cm}^{-3}\right)$ by $65 \%$ for $r>15 \mathrm{~nm}$, decreasing to $2 \%$ for $r>50 \mathrm{~nm}$. Activation of $\mathrm{OIO}$ by $\mathrm{H}_{2} \mathrm{SO}_{4}$ vapours increased the aerosol population by $226 \%$ for $r>15 \mathrm{~nm}$, decreasing to $0.5 \%$ for $r>50 \mathrm{~nm}$. When the latter case was considered with an additional condensable low volatility vapour with a concentration of $1.2 \times 10^{7}$ molecules $\mathrm{cm}^{-3}$, the largest increase in aerosol concentration was observed where the aerosol concentration increased by $615 \%$ for sizes 


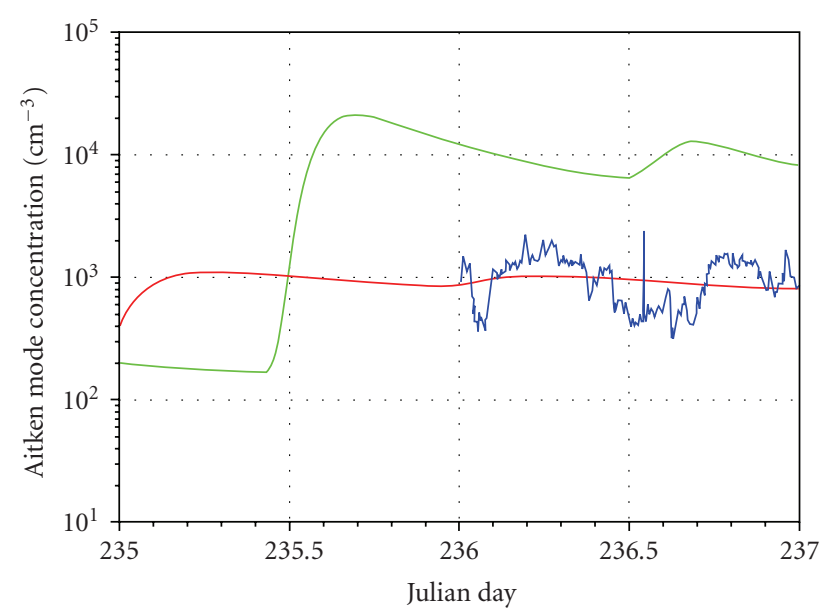

- Modal model Aitken mode concentration

- Measured Aitken mode concentration

— Sectional model Aitken mode concentration

(a)

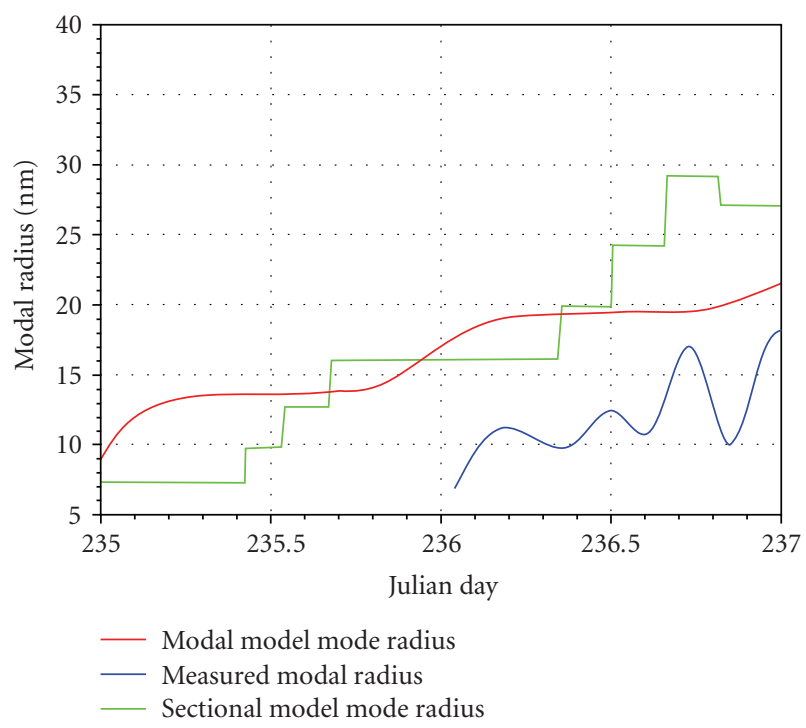

(b)

Figure 6: (a) Comparison of mode concentration and (b) mode radius between modeled and measured plumes.

$r>15 \mathrm{~nm}$ and by $15 \%$ for $r>50 \mathrm{~nm}$. For the clean marine cases considered, where the total aerosol concentration was $300 \mathrm{~cm}^{-3}$, after a nucleation burst via activation of OIO by $\mathrm{H}_{2} \mathrm{SO}_{4}$ vapours, and subsequent growth by a low volatility organic vapour, peak Aitken mode particle concentrations exceeded $3000 \mathrm{~cm}^{-3}$, while the concentration at the end of two days of simulations at sizes $r>15, r>25, r>35$, and $r>50 \mathrm{~nm}$ were $1585 \mathrm{~cm}^{-3}, 556 \mathrm{~cm}^{-3}, 230 \mathrm{~cm}^{-3}$, and $126 \mathrm{~cm}^{-3}$, respectively, suggesting that the combination of iodine oxide activation by sulphuric acid and subsequent growth by an organic vapour can significantly impact on the marine aerosol population number concentration. Changes of these magnitudes can have notable impact on marine stratiform cloud properties given the susceptibility of such clouds. A comparison case study analysis using the modal model and a sectional model displays reasonably good results. Despite the mode-jumping associated with modal models, the growth of the Aitken mode was predicted quite well and suggests that a modal model is suitable for large scale modelling applications.

\section{Acknowledgments}

This work was supported by the European Commission under the EUCAARI Integrated Project and the MAP Specifically Targeted Research Project. In addition, the work was supported by Ireland's Higher Education Authority under the PRTLI4 programme: Environment and Climate: Impact and Responses.

\section{References}

[1] IPCC, "Summary for policymakers"” in Climate Change 2007: The Physical Science Basis. Contribution of Working Group I to the Fourth Assessment Report of the Intergovernmental Panel on Climate Change, S. Solomon, D. Qin, M. Manning et al., Eds., Cambridge University Press, Cambridge, UK, 2007.

[2] R. J. Charlson, J. E. Lovelock, M. O. Andreae, and S. G. Warren, "Oceanic phytoplankton, atmospheric sulphur, cloud albedo and climate," Nature, vol. 326, no. 6114, pp. 655-661, 1987.

[3] L. Pirjola, C. D. O’Dowd, I. M. Brooks, and M. Kulmala, "Can new particle formation occur in the clean marine boundary layer?" Journal of Geophysical Research D, vol. 105, no. 21, pp. 26531-26546, 2000.

[4] C. D. O’Dowd, J. L. Jimenez, R. Bahreini et al., "Marine aerosol formation from biogenic iodine emissions," Nature, vol. 417, no. 6889, pp. 632-636, 2002.

[5] C. D. O'Dowd, M. Geever, M. K. Hill, M. H. Smith, and S. G. Jennings, "New particle formation: nucleation rates and spatial scales in the clean marine coastal environment," Geophysical Research Letters, vol. 25, no. 10, pp. 1661-1664, 1998.

[6] C. O’Dowd, G. McFiggans, D. J. Creasey et al., "On the photochemical production of new particles in the coastal boundary layer," Geophysical Research Letters, vol. 26, no. 12, pp. 1707-1710, 1999.

[7] C. D. O.'Dowd and T. Hoffmann, "Coastal new particle formation: a review of the current state-of-the-art," Environmental Chemistry, vol. 2, no. 4, pp. 245-255, 2005.

[8] S. Pechtl, E. R. Lovejoy, J. B. Burkholder, and R. von Glasow, "Modeling the possible role of iodine oxides in atmospheric new particle formation," Atmospheric Chemistry and Physics, vol. 6, no. 2, pp. 505-523, 2006.

[9] A. Saiz-Lopez, J. M. C. Plane, G. McFiggans et al., "Modelling molecular iodine emissions in a coastal marine environment: the link to new particle formation," Atmospheric Chemistry and Physics, vol. 6, no. 4, pp. 883-895, 2006.

[10] H. Vuollekoski, V.-M. Kerminen, T. Anttila et al., "Iodine dioxide nucleation simulations in coastal and remote marine environments," Journal of Geophysical Research D, vol. 114, no. 2, Article ID D02206, 2009.

[11] E. Vignati, J. Wilson, and P. Stier, "M7: an efficient sizeresolved aerosol microphysics module for large-scale aerosol transport models," Journal of Geophysical Research D, vol. 109, no. 22, pp. 1-17, 2004.

[12] M. Dall'Osto, D. Ceburnis, G. Martucci et al., "Aerosol properties associated with air masses arriving into the North 
East Atlantic during the 2008 Mace Head EUCAARI intensive observing period: an overview," Atmospheric Chemistry and Physics, vol. 10, no. 17, pp. 8413-8435, 2010.

[13] M. Ehn, H. Vuollekoski, and T. Petäjä, "Growth rates during coastal and marine new particle formation in Western Ireland," Journal of Geophysical Research, vol. 115, Article ID D18218, 11 pages, 2010.

[14] C. O'Dowd, C. Monahan, and M. Dall'Osto, "On the occurrence of open ocean particle production events," Geophysical Research Letters, vol. 37, Article ID L19805, 2010.

[15] N. A. Fuchs, Evaporation and Droplet Growth in Gaseous Media, Pergamon, New York, NY, USA, 1959.

[16] H. Berresheim, T. Elste, H. G. Tremmel et al., "Gas-aerosol relationships of $\mathrm{H}_{2} \mathrm{SO}_{4}, \mathrm{MSA}$, and $\mathrm{OH}$ : observations in the coastal marine boundary layer at Mace Head, Ireland," Journal of Geophysical Research D, vol. 107, no. 19, article no. 8100, 2002.

[17] H. Korhonen, K. E. J. Lehtinen, and M. Kulmala, "Multicomponent aerosol dynamics model UHMA: model development and validation," Atmospheric Chemistry and Physics, vol. 4, pp. 757-771, 2004. 

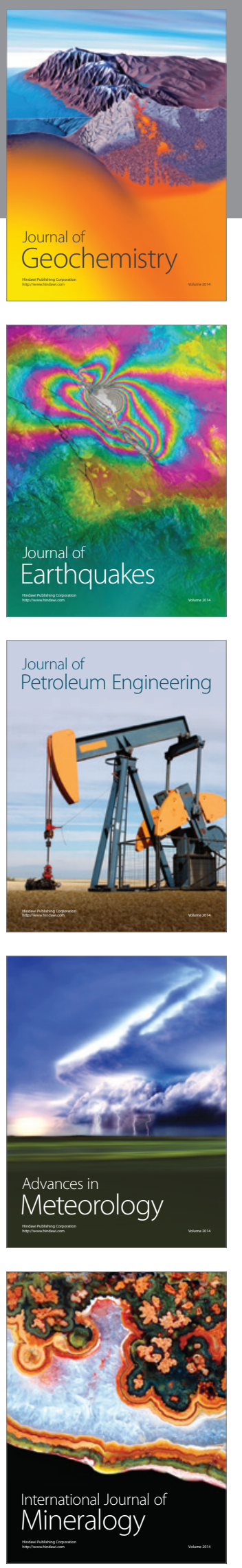
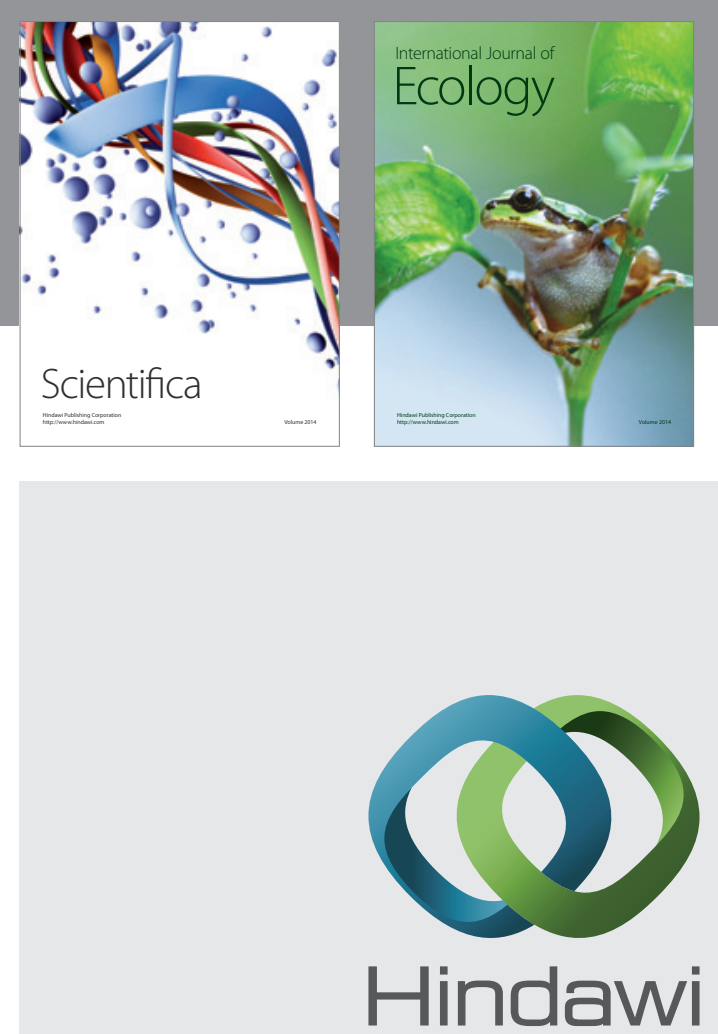

Submit your manuscripts at http://www.hindawi.com
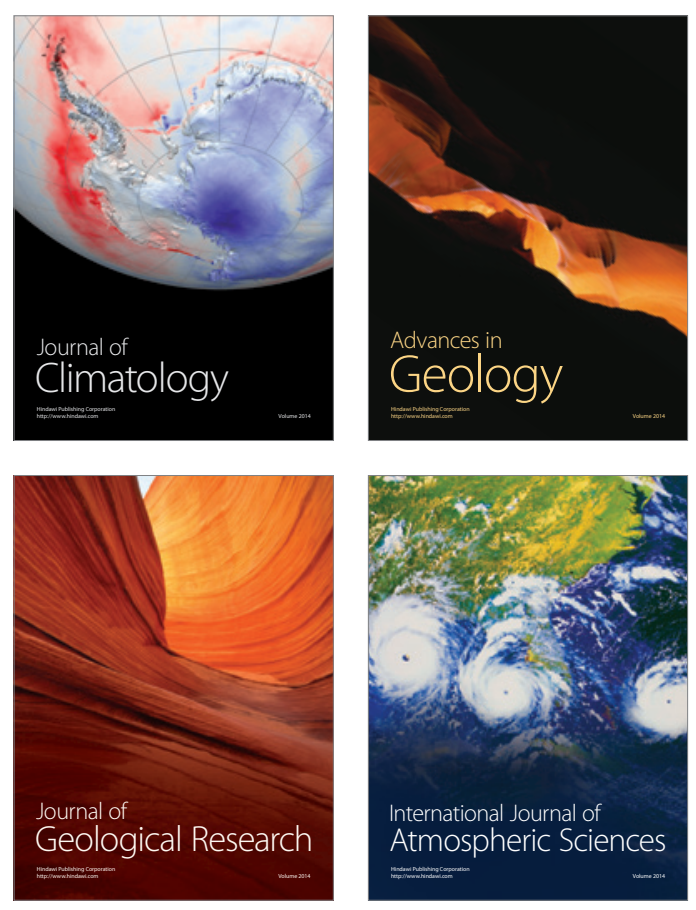
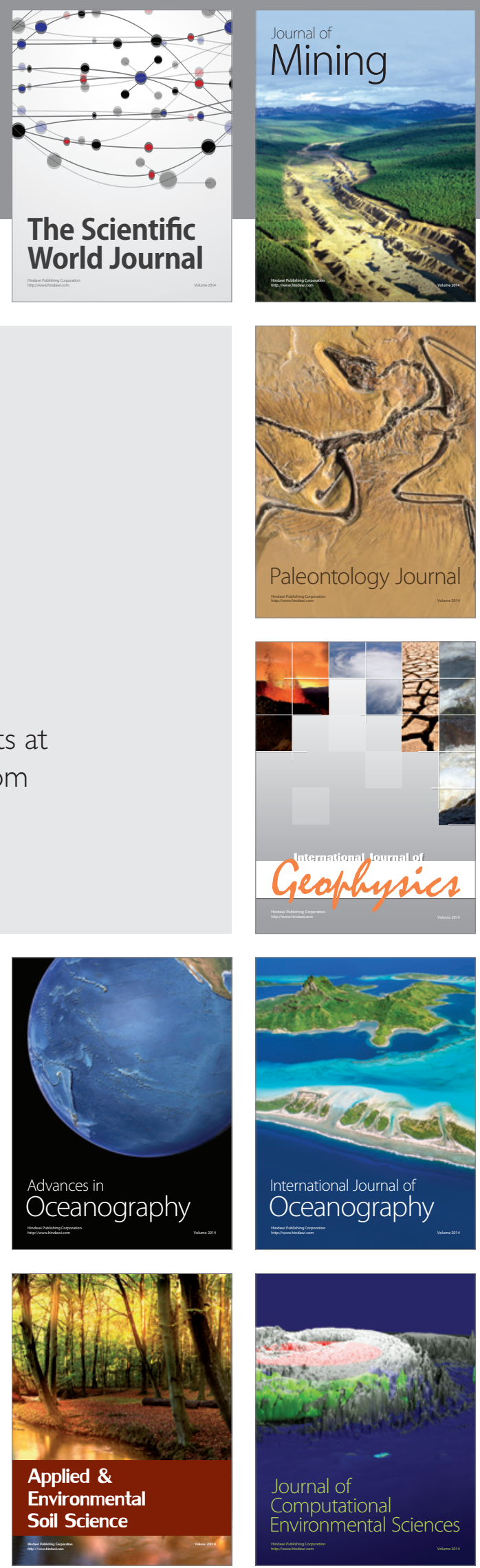